\title{
INSTRUMENTATION AND SOFTWARE FOR LOW-LEVEL LIQUID SCINTILLATION COUNTING RADIOCARBON DATING
}

\author{
GUAN SANYUAN and XIE YUANMING
}

Beijing Nuclear Instrument Factory, P. O. Box 8800, Beijing 100020 China

\begin{abstract}
In China, the development of ${ }^{14} \mathrm{C}$ dating is closely related to that of liquid scintillation counting (LSC). New demands are continuously made on LSC by ${ }^{14} \mathrm{C}$ dating, and at the same time, the development of LSC promotes ${ }^{14} \mathrm{C}$ dating. demands are continuously made on LSC by ${ }^{14} \mathrm{C}$ dating, and at the same time, the development of of History, Peking University. This has laid the foundation for ${ }^{14} \mathrm{C}$ dating by $\beta$ counting with LS counters. Initially, we used a modified conventional LS counter. Despite its poor detection efficiency and high background, it did make a great contribution to ${ }^{14} \mathrm{C}$ dating and LSC in China. Additional ${ }^{14} \mathrm{C}$ laboratories were established for the fields of archaeology, geology, geography, vertebrate paleontology, marine geology and seismology, for which ${ }^{14} \mathrm{C}$ dating is becoming an important research tool. At present, over $50{ }^{14} \mathrm{C}$ laboratories have been established in China; $90 \%$ of the labs use LS counters for $\beta$ counting, most of which are manufactured in China. ${ }^{14} \mathrm{C}$ dating in China has been primarily concerned with sample synthesis techniques. Since 1979, we have developed three types of LS counters. One is of conventional design; the others are with anticoincidence shielding. We describe here an anticoincidence-shielded LS counter.
\end{abstract}

\section{INTRODUCTION}

We describe here a low-level coincidence liquid scintillation (LS) counter with anticoincidence shielding, which is mainly used for $\beta$ counting. The counter consists of sample detector, sample chamber, anticoincidence detector and shielding, electronic measuring circuits and sample-changing mechanism, computer and software. For dating of samples over $20 \mathrm{ka}$, count rate per gram of benzene is less than $1 \mathrm{cpm}$, so that the instrument must be designed with sufficiently high detection efficiency, very low background and good long-term stability and reproducibility. To increase the sensitivity of the instrument, it is necessary to raise the detection efficiency, reduce the background or extend the measurement time. However, it is difficult to raise detection efficiency and we prefer not to extend measurement time. Thus, reducing the background has become of special interest to designers of LS counters.

\section{DETECTOR ASSEMBLY}

The detector assembly consists of a photomultiplier tube (PMT), sample chamber, sample vial and preamplifier. The key part of the LS counter, the PMT, must have high-quantum efficiency, low noise level and little radioactivity in the casing material to reduce the background of the instrument. We compared PMTs, RCA 4501-V4, EMI 9801, EMI 9820 and Chinese-made GDB-48, and decided to use the RCA $4501-\mathrm{V} 4$ and GDB-48. By selecting pairs under ${ }^{14} \mathrm{C}$ operating conditions, $\mathrm{HV} \sim 1300 \mathrm{~V}$, the noise of the RCA $4501-\mathrm{V} 4$ is only $10^{2} \mathrm{cpm}$. When the circuit coincidence time is $50 \mathrm{~ns}$, the contribution of accidental coincidence counts of the background can be ignored. The other principle of PMT selection for the possible reduction in background is the contribution of the cross-talk counts and radiation in glass casing material.

The sample chamber is in contact with the PMT to increase its light-gathering power. Many researchers have carried out special studies of chamber geometry, construction material and reflective coating. We use brass as the material of choice for the sample chamber; $\mathrm{MgO}$ serves as the reflecting layer, as its surface has superior scattering reflection, of which light-gathering power to the PMT is better than that of a mirror reflection. The inside diameter of the chamber is $29 \mathrm{~mm}$, which can accommodate a $28 \mathrm{~mm}$ sample vial. Figure 1 shows the configuration of the sample chamber. 


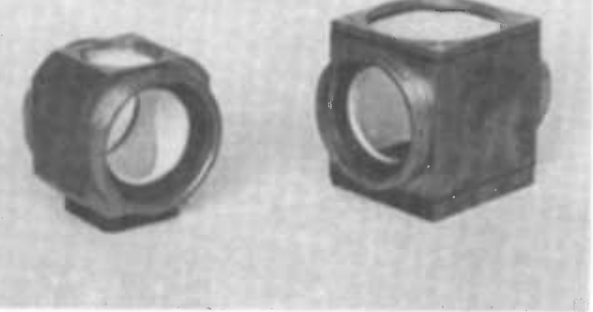

Fig. 1. Sample chamber

The conventional LS counter has few low-background requirements for the sample vial except transmittance and size. Ordinary low-potassium glass or plastic is certainly sufficient for vial construction. However, for the low-level counter, the vial material must be specially selected for excellent transmittance in the ultra-violet range, good sealability, proper outer diameter and wall thickness.

We compared vials of different materials, and concluded that teflon is the best; quartz took second place. The performance of the teflon vial is superior. The vial is fabricated from a bar by lathing and includes lid, inner stopper, body and base. The lid and base are brass, the inner stopper and body are teflon. The outer diameter is $28 \mathrm{~mm}$, wall thickness $0.8 \mathrm{~mm}$, height $56.5 \mathrm{~mm}$ (including lid and base) and volumes $3 \mathrm{ml}$ and $7 \mathrm{ml}$. Figure 2 shows the teflon vial.

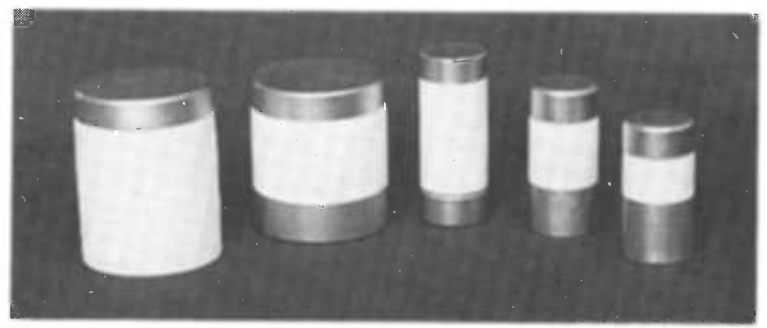

Fig. 2. Teflon sample vial

In order to ensure measurement accuracy, the vial should have good sealability and little weight loss (with benzene solution in it) for a year. Leakage can be detected by weighing. The weight of the vial body is controlled to within $\pm 100 \mathrm{mg}$. The drawback of the teflon vial is that its surface can readily take up static charge, causing spurious counts. The vial body design eliminated these counts.

\section{MASSIVE SHIELDING AND ANTICOINCIDENCE SHIELDING}

Reasonable, effective shielding is important for reducing background in a low-level LS counter. We use low-background lead, $7.5 \mathrm{~cm}$ thick, lined with $4 \mathrm{~cm}$ of stainless steel as the main shielding material in our instrument. This shielding effect has provided superior performance. The total weight is $1500 \mathrm{~kg}$.

Massive shielding can considerably reduce the background of the instrument, but it cannot stop high-energy gamma rays originating in the environment and the hard component in cosmic rays. Anticoincidence shielding, however, is the most effective way to decrease the contribution of these rays to the background. 
We compared $\mathrm{NaI}(\mathrm{Tl})$ crystal and plastic scintillator anticoincidence detectors with the same shape and size. The $\mathrm{NaI}(\mathrm{Tl})$ crystal offered a better anticoincidence effect because it has a higher stopping power to $\gamma$ rays than the plastic scintillator. Figure 3 shows the $\mathrm{NaI}(\mathrm{Tl})$ anticoincidence crystal that we use. It is constructed by overlaying two $200 \times 100 \mathrm{~mm}$ diameter crystals.

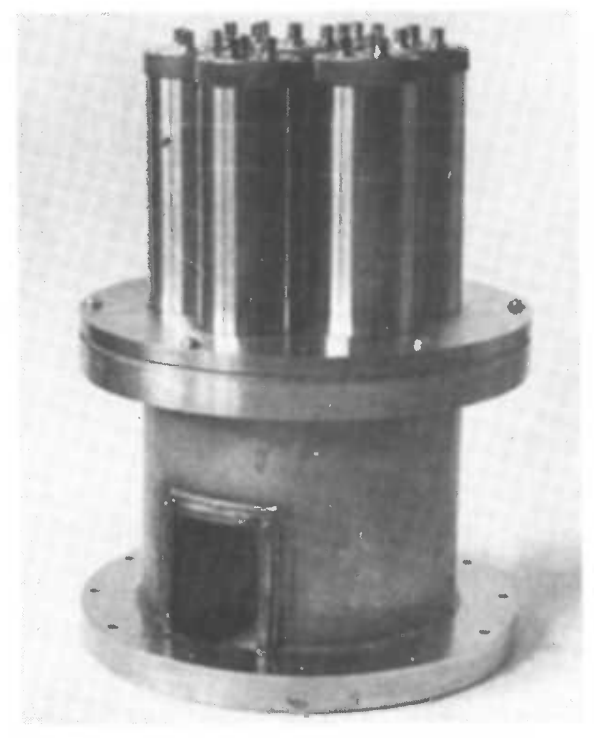

Fig. 3. Anticoincidence detector

A hole, $80 \times 65 \times 195 \mathrm{~mm}$, is made in the lower side for placement of the PMT and the sample chamber. The crystal is sealed by a stainless-steel cover with 7 optical windows on the upper part for the 7 used to collect the signals from the $\mathrm{NaI}(\mathrm{Tl})$ crystal. Table 1 shows the background counts measured at the same detection efficiency with and without anticoincidence. The anticoincidence detector reduces the background by $82 \%$.

TABLE 1. Background of the empty chamber and empty vial count rate (cpm) of the counter at the same efficiency, with and without anticoincidence

\begin{tabular}{llccc}
\hline Efficiency & Operating conditions & $\begin{array}{c}\text { Background } \\
(\mathrm{cpm})\end{array}$ & $\begin{array}{c}\text { Empty } \\
\text { chamber } \\
(\mathrm{cpm})\end{array}$ & $\begin{array}{c}\text { Empty vial } \\
(\mathrm{cpm})\end{array}$ \\
\hline${ }^{14} \mathrm{C}, 5 \mathrm{ml}$ & Without anticoincidence & 2.23 & 1.27 & 2.20 \\
$76.3 \%$ & With anticoincidence & 0.40 & 0.17 & 0.10 \\
\hline
\end{tabular}

Many factors contribute to the background of the LS counter. These include accidental coincidence PMT noise, cross-talk, radiation from the environment and materials used in instrument manufacture, the scintillation solution, itself, and Cerenkov light from the sample vial. Many researchers have extensively analyzed these contributions. We studied the cross-talk counts and believe that they are caused mainly by the Cerenkov effect of the high-energy $\gamma$ rays in the environment and the hard components in the cosmic rays on the transparent window end of the PMT. Anticoincidence shielding is an effective way to greatly reduce cross-talk counts. 


\section{ELECTRONIC MEASURING SYSTEM AND AUTOMATIC SAMPLE CHANGER}

A schematic of the electronic measuring system is shown in Figure 4. Coincidence signals from the two PMTs are added together, processed through the coincidence and anticoincidence circuitry, entered via a linear gate and analyzed by a multichannel analyzer. The coincidence resolution time used is ca. $50 \mathrm{~ns}$ with an anticoincidence shaping time of $2 \mu \mathrm{s}$. It is desirable to keep the coincidence shaping time to a minimum; otherwise, it may have some effect on the efficiency. Because the samples for ${ }^{14} \mathrm{C}$ dating are of low activity, the high-count-rate samples are not taken into special consideration in our electronic circuits; usually $1 \times 10^{4} \mathrm{dpm}$ or so are selected. We use a disk-type automatic sample charger that can accommodate ten samples at a time. The samples move up and down in a dark box and are coded in the top position. To ensure that there is no damage to the PMT, the dark box is designed with an interlocking lid to shut off $\mathrm{HV}$ from the PMT when samples are placed in or removed from the counter.

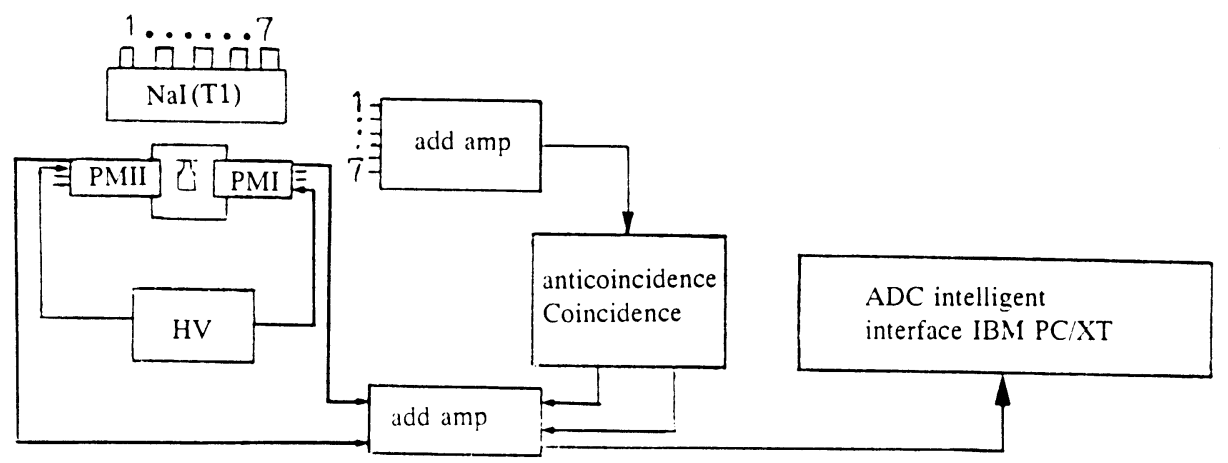

Fig. 4. Electronic measuring system

\section{HARDWARE AND SOFTWARE}

The computer data acquisition and processing system consists of an analog-to-digital converter, intelligent interface, IBM PC/XT, interface for sample automatic changing, as well as ${ }^{14} \mathrm{C}$ application software. Figure 5 is a schematic of the computer system.

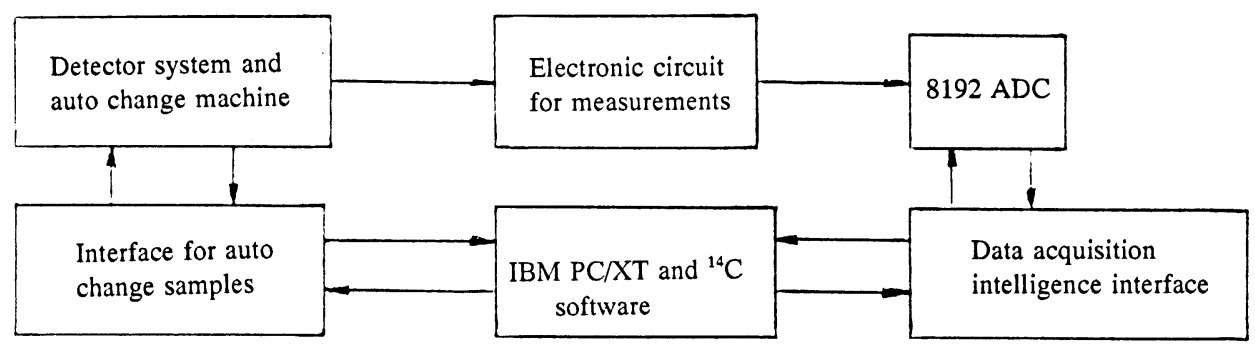

Fig 5. Computer system

The AT software package is used for low-level LSC control. It can measure automatically, display and process ${ }^{14} \mathrm{C}$ data. Its features are:

1. Tree structure and function keys

2. Distinct spectra display using supporting Color-400 high-resolution display

3. Rapid processing speed using FORTRAN 77, 8088 and 8087 Macro assembly 
4. Automatic cyclic and repeat measurements for up to ten samples. Sample measurement time can be set specifically for 1-1000 minutes.

5. Numerous and varied functions, such as automatic and manual measurements, system efficiency and stability and data processing for ${ }^{14} \mathrm{C}$ and ${ }^{3} \mathrm{H}$.

Manual measurement includes setting parameters, collecting data, spectra input and output and data processing, such as smoothing, peaking, finding area and FWHM. These functions can be used for system adjustment, selecting reasonable measurement time and other parameters. The user can also erase the measurement of incorrect data points, which can be replaced by new data. The program is able to check the data using three different methods, and display the results.

During measurement, the program controls the system to complete automatic change of samples, sample stabilization, clear data, auto start and stop, determine the counting sum, store data to disk and display spectra in real time. After measurement, the program checks every datum in three ways and displays the results. In case of an electrical failure, the user can recover measurements manually. All data can be stored; only the one being measured at the time of a failure will be lost.

The program can calculate ${ }^{14} \mathrm{C}$ ages and standard deviations. $\mathrm{A}{ }^{14} \mathrm{C}$ analysis report is shown in Figure 6.

\section{RESULTS OF EXPERIMENTS}

A 5-ml background solution was counted in a 7-ml-volume sample vial using a scintillation solution of PPO + POPOP while measuring background over 2000 min (Table 2).

TABLE 2. Counter Detection Efficiency and Background

\begin{tabular}{cccccc}
\hline Vial type & $\begin{array}{c}\text { Efficiency } \\
(\mathrm{E}) \%\end{array}$ & $\begin{array}{c}\text { Black vial } \\
\text { count/min }\end{array}$ & $\begin{array}{c}\text { Empty vial } \\
\text { count/min }\end{array}$ & $\begin{array}{c}\text { Background } \\
\text { (B) } \\
\text { count/min }\end{array}$ & $\begin{array}{c}\text { Quality } \\
\mathrm{Q}=\mathrm{E}^{2} / \mathrm{B}\end{array}$ \\
\hline Teflon & 76.3 & $0.10 \pm 0.02$ & $0.13 \pm 0.02$ & $0.40 \pm 0.02$ & 14,500 \\
Quartz & 77.0 & $0.10 \pm 0.02$ & $0.15 \pm 0.02$ & $0.43 \pm 0.02$ & 13,700 \\
\hline
\end{tabular}

The long sample measurement time of ${ }^{14} \mathrm{C}$ dating requires long-term stability of the instrument. We checked 1000-min background and 10-min efficiency during $4000 \mathrm{~min}$ of continuous counting. The results are shown in Table 3.

In order to test the measurement reliability of the counter and the normal operation of the computer software, we measured sugar carbon (modern carbon (1) standard used in China), background and known-age samples. The results are given in Table 4.

Besides being used for $\beta$ counting in ${ }^{14} \mathrm{C}$ dating, our LS counter can be used for measurement of ${ }^{3} \mathrm{H}$ low-level samples. The data-processing software also includes calculations of both electrolytically- and non-electrolytically-enriched ${ }^{3} \mathrm{H}$ samples.

TABLE 3. Long-Term Stability of the Counter

\begin{tabular}{cccccc}
\hline Object & 1 & 2 & 3 & 4 & Average \\
\hline $\begin{array}{l}{ }^{14} \mathrm{C} \text { source effi- } \\
\text { ciency (\%) }\end{array}$ & 76.3 & 76.3 & 76.3 & 76.6 & 76.4 \\
Background (cpm) & $0.40 \pm 0.02$ & $0.45 \pm 0.02$ & $0.40 \pm 0.02$ & $0.38 \pm 0.02$ & $0.41 \pm 0.02$ \\
\hline
\end{tabular}


TABLE 4. Results of measurements on sugar carbon, background and known-age samples

\begin{tabular}{clcccccc}
\hline No. & Sample & $\begin{array}{c}\text { Weight } \\
\mathrm{C}_{6} \mathrm{H}_{6} \mathrm{~g}\end{array}$ & Count (cpm) & $\begin{array}{c}\text { Efficiency } \\
(\%)\end{array}$ & $\begin{array}{c}\text { Known age of } \\
\text { sample (yr BP) }\end{array}$ & $\begin{array}{c}\text { Result } \\
(\mathrm{yr} \text { BP) }\end{array}$ & Submitter* \\
\hline 1 & Background & 3.6200 & $0.48 \pm 0.02$ & -- &.- &.- & IA \\
2 & Sugar carbon 1 & 3.1340 & 40.40 & 74.5 & - & - & IA \\
3 & Sugar carbon 2 & 3.3270 & 43.69 & 76.8 & - & 5737 & PU \\
4 & Specimen 1 & 3.5400 & 17.02 & -- & 5780 & $5762 \pm 108$ & IA \\
5 & Specimen 2 & 3.3176 & 27.17 & -- & 1250 & $1244 \pm 98$ & IA \\
\hline
\end{tabular}

"IA = Institute of Archaeology; PU = Peking University

\section{**** ${ }^{14} \mathrm{C}$ ANALYSIS REPORT **** 25/May/1990}

SAMP.: 4 LOOP: 12 Repeat: 2 Time: $20(\mathrm{~min})$

\begin{tabular}{|c|c|c|c|c|c|c|c|c|}
\hline & & & & & & . & & \\
\hline No. & Name & $\begin{array}{l}\text { Weight } \\
(\mathrm{g})\end{array}$ & $\begin{array}{l}\text { Rate } \\
(\mathrm{cpm})\end{array}$ & Error & $\begin{array}{c}\text { Age } \\
\mathrm{T}=5730 \mathrm{yr}\end{array}$ & Error & $\begin{array}{c}\text { Age } \\
\mathrm{T}=5568 \mathrm{yr}\end{array}$ & Error \\
\hline 1 & MODC & 4.521 & 58.701 & .349 & & & & \\
\hline 2 & BACKG & 4.521 & .396 & .029 & & & & \\
\hline 3 & $\mathrm{ABC} 1$ & 4.432 & 12.913 & .164 & 10005 & 258 & 9721 & 243 \\
\hline 4 & $\mathrm{ABC} 2$ & 4.422 & .514 & .032 & 48834 & 2051 & 47449 & 1983 \\
\hline No. & Name & Weight & Rate & Error & & & & \\
\hline 1 & MODC & 4.521 & 58.701 & .349 & & & & \\
\hline
\end{tabular}

Measuring counts per 20 minutes:

$\begin{array}{llllllll}1075 & 1153 & 1165 & 1175 & 1085 & 1205 & 1225 & 1183 \\ 1170 & 1215 & 1243 & 1205 & 1195 & 1152 & 1150 & 1179 \\ 1183 & 1095 & 1199 & 1157 & 1253 & 1123 & 1136 & 1230\end{array}$

No. Name Weight Rate Error

2 BACKG $4.521 \quad .396 \quad .029$

Measuring counts per 20 minutes:

$\begin{array}{llllllll}10 & 7 & 4 & 11 & 11 & 8 & 6 & 11\end{array}$

$\begin{array}{llllllll}10 & 6 & 4 & 10 & 5 & 9 & 5 & 7\end{array}$

$\begin{array}{llllllll}6 & 8 & 8 & 11 & 7 & 10 & 9 & 7\end{array}$

No. Name Weight Rate Error

$\begin{array}{lllll}3 & \mathrm{ABC} 1 & 4.423 & 12.913 & .029\end{array}$

Measuring counts per 20 minutes:

$\begin{array}{llllllll}253 & 255 & 247 & 253 & 272 & 257 & 274 & 283 \\ 265 & 257 & 279 & 260 & 248 & 251 & 243 & 256 \\ 253 & 254 & 264 & 264 & 260 & 270 & 221 & 257\end{array}$

Fig. $6 .{ }^{14} \mathrm{C}$ analysis report 


\section{ACKNOWLEDGMENTS}

The authors wish to thank Wang Zhiyuan, Dai Zhude, Xu Shengkui and Qu Xin for taking part in the development of this counter. Also helpful were the ${ }^{14} \mathrm{C}$ Laboratory of the Institute of Archaeology, Chinese Academy of Social Sciences and the ${ }^{14} \mathrm{C}$ Laboratory of the Department of History, Peking University. We thank Henry Polach, Australian National University, for useful discussions. 